\title{
Investor Behavior during COVID-19
}

\author{
Haoyan Gu* \\ University of California, Santa Barbara, CA 93106, U.S.A. \\ *Corresponding author: Haoyan Gu, haoyangu0615@163.com
}

\begin{abstract}
As COVID-19 spread throughout the whole world last year, many aspects of human lives were impacted by it. In order to learn of its influences on the financial market, many scholars started their own research in different ways. This paper reviews three different groups of scholars' studies about the influences of COVID-19 on investor behavior in the financial market.
\end{abstract}

Keywords: Financial market; Behaviors; COVID-19

Publication date: August 2021; Online publication: August 30, 2021

\section{Introduction}

It has been generally acknowledged that COVID-19 had brought many negative fluctuations to everyday life as well as the economy of the human society. The spread of COVID-19 resulted in significant financial decrease with rising risks in the financial market. In order to study investor behavior under the influences of COVID-19, some researchers focused on research and had published their results.

\section{Signal acquisition}

Regina Ortmann, Matthias Pelster, and Sascha Tobias Wengerek published their research on May 3, 2020, on the Social Science Research Network. They analyzed how the behaviors of retail investors changed in the market under the impact of COVID-19 ${ }^{[1]}$. The respondents involved had lower general preferences for risks, were less willing to invest under risks, and had less optimistic expectations on the market. As a result, many investors might reduce their market exposure and avoid risk-taking. According to the data, the average weekly trading intensity increased by $13.9 \%$ as the number of COVID-19 cases doubled ${ }^{[1]}$. Overall, the investors added more money into their accounts, creating new accounts and positions.

According to the research, the researchers used a transactional-level brokerage data from a discount broker that offered an online trading platform to retail investors under a UK broker license ${ }^{[1]}$. That data contained investors' trades from August 1, 2019, to April 17, 2020. Specifically, it included 45,003,637 transactions that were executed by 456,365 investors, deposits from the brokerage accounts, notifications of informing investors of volatility events, and basic demographic information. The method that the researchers used to analyze the relation between the spread of COVID-19 and the trading activities of investors was the ordinary least squares (OLS) regression ${ }^{[1]}$. There were several variables to represent the trading activities. For example, they used the number of trades to estimate the trading intensity while leverage was used to measure the risk in the trade ${ }^{[1]}$. For short sales, a trade receives the value of one when it established a short position. In contrast, a trade received the value of zero when it did not establish a short position. Furthermore, the researchers used other variables to determine the spread of the pandemic where COVID-19 referred to the logarithm of the number of corona cases plus one. In addition, the researchers employed three variables to separate various stages of the pandemic. 
Based on the data, the researchers found out that the trading activities increased as COVID-19 spread. Specifically, the respondents did not move to either an extremely safe or risky trade. From February 23 to March 22, the investors raised their tendency to execute short selling. After March 12, investors tended to reduce their leverage-usage because they wanted to make more risk-averse choices. The researchers claimed that the data sample they had selected might not represent the normal families. Although there was a limitation to this research, the researchers were still optimistic about their research to provide helpful insights in regard to investors' trading activities under the pressure of COVID-19.

Ivo Welch published a research about investor behavior based on the impact of COVID-19 on December 8, 2020, on the Social Science Research Network. According to this article, it was generally acknowledged that Robinhood ( $\mathrm{RH})$ investors increased their holdings ${ }^{[2]}$. Those investors tended to invest in portfolios with high past share volume and dollar-trading volume. From mid-2018 to mid-2020, Robinhood investors did well in timing and investing in consensus portfolios ${ }^{[2]}$. First, Robinhood is an online report brokerage that helps investors to invest easily and cheaply in the stock market. All the data is downloaded on scripts which are run by Robintrack.net, and they are publicly available on this platform. Due to the reason that 2020 was a year that included extreme events, the researchers had an easier opportunity to observe the behaviors of people during normal and stressed times.

According to the research, the researchers found out that retail investors may behave differently to extreme events ${ }^{[2]}$. The author stated that the Standard and Poor's (S\&P) 500 fell to 2,237 in March, which was a 33\% decrease compared to one month ago. Some people expected the economic recession to continue. However, the stock market increased to 3,000 and reached its all-time highs in December. Based on the data from Robintrack.net, the growth rate of 3\% per trading day ended in March 2020. The deepest RH growth happened simultaneously with the COVID-19 onset and declined in the stock market ${ }^{[2]}$. At the starkest decline in the market, $\mathrm{RH}$ investors did not retreat. Moreover, some of the behaviors of the $\mathrm{RH}$ investors were ridiculed ${ }^{[2]}$. For example, some of them overweighted some unusual portfolios. In 2020, several researchers such as Barber and Huang showed that RH investors performed badly timed actions in the market. However, other researchers such as Cheng, Murphy, and Kolanovic reported that RH investors performed good-timing actions on average ${ }^{[2]}$. In regard to important holdings, in 2018, people favored investing in companies like Ford, Apple, and Microsoft. However, investors increased their investment in Disney, GE, Ford, and airline stocks in mid-2020 ${ }^{[2]}$. For example, American Airlines' weight rose from $0.12 \%$ to $2.39 \%$ in the actual RH (ARH) crowd portfolio. According to the researcher's interpretation, people had changed their taste to invest in "old economy" stocks ${ }^{[2]}$.

In conclusion, RH investors increased their holdings in individual stocks when the market was influenced by COVID-19 in March 2020. They did not express fear in the market according to their performances instead they performed well in terms of timing and investing. RH investors favored investing in stocks that retained an above-average trading volume over the previous year. As illustrated above, the investors tended to invest in old economy firms like airline companies in 2020. The RH consensus portfolio made a great performance in the cross-section, earning positive alphas with the risk-free rate, market model, and the Fama-French five-factor model. In addition, the past performance helps to explain why RH investors kept pouring the market under the impact of COVID-19.

Manish Talwar, Shalini Talwar, Puneet Kaur, Naliniprava Tripathy, and Amandeep Dhir published their research paper, "Has financial attitude impacted the trading activity of retail investors during the COVID-19 pandemic?" on October 9, $2020^{[3]}$. According to their paper, people's financial behaviors were influenced by their financial attitude because of the impact made by COVID-19 ${ }^{[3]}$. Extensive uncertainty and panic were created by COVID-19. Therefore, it is important to study the financial attitude of investors. 
Investing under such a pandemic is risky. This research examined the impacts on the trading activity of retail investors when the pandemic of COVID-19 happened from six dimensions: financial attitude; namely, financial anxiety; optimism; financial security; deliberative thinking; interest in financial issues; needs for precautionary savings ${ }^{[3]}$. The researchers collected data from 404 respondents and used the artificial neural network (ANN) to analyze ${ }^{[3]}$. The results of this research showed that the six dimensions had a positive influence on trading activities.

Based on previous scholar's research, those six dimensions that were mentioned above were used to measure the investors' financial attitude. The researchers adapted pre-validated scales used by previous scholars in behavioral finance and developed their own survey questionnaire. They used four items to measure financial anxiety; three items to measure financial security and optimism; two items to measure deliberate thinking, interest in financial issues, and needs for precautionary savings ${ }^{[3]}$.

In addition, the researchers used a five-point scale in the questionnaire. In June 2020, the researchers used the snowball sampling method to choose the respondents. All the respondents were between 25 to 40 years old, and they had traded in the stock market. In regard to the model used, according to previous researchers' experience, they chose the artificial neural network to analyze the data. In order to minimize errors, they experimented with several rounds of the learning process. Through these processes, the information learned were then stored as synaptic weights in the model. This study used six inputs, two hidden, and one output neuron to generate. In order to avoid overfitting, $70 \%$ of the data was used as the training data in the research. The results of the research showed that there was no linear relationship between the dependent variable and retail investors' trading activity with four of the independent variables; namely, financial security, deliberate thinking, interest in financial issues, and needs for precautionary savings. In order to determine the research bias, the researchers used Harman's single factor test. The results showed a single factor explained $34.53 \%$ of the total variance which was below the cut-off of $50 \%$. To test the validity and reliability, the researchers calculated the prescribed validity and reliability measures. Then, they compared them with the recommended cut-off where all the results of the prescribed validity and reliability measures conformed to the cut-off. The result of ANN showed that there was a high accuracy of prediction in the model. As a result, the interest in financial issues had been influenced the most, followed by deliberative thinking, needs for precautionary savings, financial security, optimism, and financial anxiety.

In conclusion, COVID-19 had led the stock market to fall dramatically when the pandemic spread. Investors perceived the stock market crash as an opportunity to invest. This research studied the trading activities under the influence of the pandemic. The researchers measured the investors' financial attitudes from six aspects: financial anxiety; optimism; financial security; deliberative thinking; interest in financial issues; needs for precautionary savings. Overall, the influence on all the six aspects were positive. Specifically, the influence on the interest in financial issues was the biggest. Then, followed by deliberative thinking and needs for precautionary savings where those two received similar influences. Financial security, optimism, and financial anxiety had minimal impacts compared to the other three aspects. To add on, a two-staged structural equation modelling-ANN (SEM-ANN) approach can be added to analyze the data by the researchers in the future.

\section{Disclosure statement}

The author declares that there is no conflict of interest. 


\section{References}

[1] Ortmann R, Pelster M, Wengerek S, 2020, COVID-19 and Investor Behavior. Financ Res Lett, TAF Working Paper, 54, TRR 266 Accounting for Transparency Working Paper Series, 25. https://papers.ssrn.com/sol3/papers.cfm?abstract_id=3589443 (accessed on January 31, 2021).

[2] Welch I, 2020, The Wisdom of the Robinhood Crowd. Journal of Finance, Forthcoming. https://papers.ssrn.com/sol3/papers.cfm?abstract_id=3696066 (accessed on January 31, 2021).

[3] Talwar M, Talwar S, Kaur P, et al., 2020, Has Financial Attitude Impacted the Trading Activity of Retail Investors during the COVID-19 Pandemic? Journal of Retailing and Consumer Services, 58. https://www.sciencedirect.com/science/article/pii/ S0969698920313497 (accessed on January 31, 2021). 